\title{
TP Model-based Robust Stabilization of the 3 Degrees-of-Freedom Aeroelastic Wing Section
}

\section{Béla Takarics, Péter Baranyi}

3D Internet-based Control and Communications Research Laboratory Institute for Computer Science and Control Hungarian Academy of Sciences 1111 Kende u. 13-17. Budapest, Hungary

E-mail: takarics.bela@sztaki.mta.hu,baranyi.peter@sztaki.mta.hu

\begin{abstract}
Active stabilisation of the 2 and 3 degrees-of-freedom (DoF) aeroelastic wind sections with structural nonlinearities led to various control solutions in the recent years. The paper proposes a control design strategy to stabilise the 3 Dof aeroelastic model. It is assumed that the aeroelastic model has uncertain parameters in the trailing edge dynamics and only one state variable, the pitch angle is measurable, therefore, robust output feedback control solution is derived based on the Tensor Product (TP) type convex representation of the aeroelastic model. The control performance requirements include robust asymptotic stability and constraint on the $l_{2}$ norm of the control signal. The control performance requirements are formulated in terms of Linear Matrix Inequalities (LMIs). As the first step of the proposed strategy, the TP type model is obtained by executing TP transformation. As the second step, LMI based control design is performed resulting in controller and observer solution defined with the same polytopic structure as the TP type model. The validation and evaluation of the derived control solutions is based on numerical simulations.
\end{abstract}

Keywords: aeroelastic wing, robust LMI-based multi-objetive control, TP model transformation, qLPV systems

\section{Nomenclature}

The variables used in the paper are defined as below:

- $a=$ non-dimensional distance from the mid-chord to the elastic axis

- $b=$ semi-chord of the wing $-m$

- $c_{h}=$ the plunge structural damping coefficients $-\mathrm{Nms} / \mathrm{rad}$ 
- $c_{l_{\alpha}}=$ aerofoil coefficient of lift about the elastic axis

- $c_{l_{\beta}}=$ trailing-edge surface coefficient of lift about the elastic axis

- $c_{m_{\alpha}, e f f .}=$ aerofoil moment coefficient about the elastic axis

- $c_{m_{\beta}, e f f .}=$ trailing-edge moment coefficient about the elastic axis

- $c_{\alpha}=$ the pitch structural damping coefficient $-\mathrm{Nms} / \mathrm{rad}$

- $h=$ plunging displacement $-m$

- $I_{\alpha}=$ the mass moment of inertia $-\mathrm{kgm}^{2}$

- $k_{h}=$ the plunge structural spring constant

- $k_{\alpha}(\alpha)=$ non-linear stiffness contribution

- $L=$ aerodynamic force $-N$

- $M=$ aerodynamic moment $-\mathrm{Nm}$

- $m=$ the mass of the wing $-k g$

- $U=$ free stream velocity $-m / s$

- $x_{\alpha}=$ the non-dimensional distance between elastic axis and the center of mass

- $\alpha=$ pitching displacement $-\mathrm{rad}$

- $\beta=$ control surface deflection - rad

- $\rho=$ air density $-\mathrm{kg} / \mathrm{m}^{3}$

\section{Introduction}

Stabilisation of aeroelastic wing section is an actively investigated research area by aerospace and control engineers with a general overview given in [1]. The Nonlinear Aeroelastic Test Apparatus (NATA) model with 3 degrees-of-freedom (DoF) and unsteady aerodynamics was designed in $[2,3]$ with several control solution approaches found in $[4,5,6,7,8,9,10,11,12,13,14,15]$ to name a few. These papers include adaptive control, nonlinear backstepping adaptive control, neural network based approach, optimal infinite-horizon control law, full-state feedforward/feedback control and other control design approaches. A mixed $H_{\infty} / H_{2}$ scheduling control system was presented in [16]. An improved 3 DoF NATA model with Linear Quadratic Regulator (LQR) control solution was proposed in [17].

Tensor Product (TP) model transformation based approach was utilised with the application of Linear Matrix Inequalities (LMIs) in several papers. Full state feedback control for the 2 DoF NATA is proposed in [18], which was improved with output 
feedback control in [19]. The control performance was further improved by manipulation of the convex hull of the polytopic model in [20]. The 2 DoF NATA was modelled with nonlinear friction in [21], which was utilised for TP model based control design in [22]. A TP model based output feedback control solution is given in [23], which is based on the improved 3 DoF aeroelastic model presented in [17].

The aim of the paper is to propose a control design strategy to robustly stabilise the NATA model given in [17] with uncertain parameters. Besides, the designed control solution has to fulfil criteria of having bounded $l_{2}$ norm of the control signal. It is assumed that the only one state, pitch angle and the free-stream velocity are measurable, therefore, output feedback control solution is utilised.

TP type convex polytopic representation of the quasi-Linear Parameter Varying (qLPV) NATA model is obtained by TP model transformation, which is immediately applied for LMI-based control design. TP model transformation is capable of determining various convex representations of the same qLPV model, as well as it can allow the qLPV model to be defined by analytical equations, soft-computing representation or given by numerical data sets. The control design and performance criteria are formulated in terms of LMIs and the control solution results in controller and observer defined by a common polytopic structure of the qLPV model.

The paper shows that defining the uncertainties of qLPV models with various structures has a large influence of the LMI feasibility tests resulting in different control performance solutions.

The paper is structured as follows: the equations of motion and the qLPV representation of the 3 DoF NATA model are given in the following section. The proposed control design methodology is introduced in Section 3 followed by the control design results in Section 4. Section 5 provides numerical simulations with evaluation and the conclusions are provided at the end of the paper.

\section{2 qLPV Model of the 3 DoF NATA Model}

The present investigation utilises the NATA model introduced by $[16,17]$. The model has three degrees of freedom: plunge $h$, pitch $\alpha$ and trailing-edge surface deflection $\beta$ and the equations of motion are the following:

$$
\begin{gathered}
\left(\begin{array}{ccc}
m_{h}+m_{\alpha}+m_{\beta} & m_{a} x_{a} b+m_{\beta} r_{\beta}+m_{\beta} x_{\beta} & m_{\beta} r_{\beta} \\
m_{a} x_{a} b+m_{\beta} r_{\beta}+m_{\beta} x_{\beta} & \hat{I}_{\alpha}+\hat{I}_{\beta}+m_{\beta} r_{\beta}^{2}+2 x_{\beta} m_{\beta} r_{\beta} & \hat{I}_{\beta}+x_{\beta} m_{\beta} r_{\beta} \\
m_{\beta} r_{\beta} & \hat{I}_{\beta}+x_{\beta} m_{\beta} r_{\beta} \hat{I}_{\beta} m x_{\alpha} b & I_{\alpha}
\end{array}\right)\left(\begin{array}{c}
\ddot{h} \\
\ddot{\alpha} \\
\ddot{\beta}
\end{array}\right)+ \\
\left(\begin{array}{ccc}
c_{h} & 0 & 0 \\
0 & c_{\alpha} & 0 \\
0 & 0 & c_{\beta_{\text {servo }}}
\end{array}\right)\left(\begin{array}{c}
\dot{h} \\
\dot{\alpha} \\
\dot{\beta}
\end{array}\right)+\left(\begin{array}{ccc}
k_{h} & 0 & 0 \\
0 & k_{\alpha}(\alpha) & 0 \\
0 & 0 & k_{\beta_{\text {servo }}}
\end{array}\right)\left(\begin{array}{c}
h \\
\alpha \\
\beta
\end{array}\right)=\left(\begin{array}{c}
-L \\
M \\
k_{\beta_{\text {servo }}} \beta_{\text {des }}
\end{array}\right) .
\end{gathered}
$$


Based on [17] $k_{\alpha}(\alpha)=25.55-103.19 \alpha+543.24 \alpha^{2}$. The quasi-steady aerodynamic force and moment is given as:

$$
\begin{gathered}
L=\rho U^{2} b C_{l_{\alpha}}\left(\alpha+\frac{\dot{h}}{U}+\left(\frac{1}{2}-a\right) b \frac{\dot{\alpha}}{U}\right)+\rho U^{2} b c_{l_{\beta}} \beta \\
M=\rho U^{2} b^{2} C_{m_{\alpha, e f f .}}\left(\alpha+\frac{\dot{h}}{U}+\left(\frac{1}{2}-a\right) b \frac{\dot{\alpha}}{U}\right)+\rho U^{2} b C_{m_{\beta, e f f .}} \beta .
\end{gathered}
$$

$L$ and $M$ above are valid for the low-velocity regime. The trailing-edge servo-motor dynamics based on [17] can be defined as:

$$
\hat{I}_{\beta} \ddot{\beta}+c_{\beta_{\text {servo }}} \dot{\beta}+k_{\beta_{\text {servo }}} \beta=k_{\beta_{\text {servo }}} \mathbf{u}_{\beta} .
$$

With the combination of equations (1), (3) and (2) one results in:

$$
\begin{aligned}
& \underbrace{\left(\begin{array}{ccc}
m_{h}+m_{\alpha}+m_{\beta} & m_{a} x_{a} b+m_{\beta} r_{\beta}+m_{\beta} x_{\beta} & m_{\beta} r_{\beta} \\
m_{a} x_{a} b+m_{\beta} r_{\beta}+m_{\beta} x_{\beta} & \hat{I}_{\alpha}+\hat{I}_{\beta}+m_{\beta} r_{\beta}^{2}+2 x_{\beta} m_{\beta} r_{\beta} & \hat{I}_{\beta}+x_{\beta} m_{\beta} r_{\beta} \\
m_{\beta} r_{\beta} & \hat{I}_{\beta}+x_{\beta} m_{\beta} r_{\beta} \hat{I}_{\beta} m x_{\alpha} b & I_{\alpha}
\end{array}\right)}_{\mathbf{M}_{\text {eom }}}\left(\begin{array}{c}
\ddot{h} \\
\ddot{\alpha} \\
\ddot{\beta}
\end{array}\right)+ \\
& +\underbrace{\left(\begin{array}{ccc}
c_{h}+\rho b S C_{l_{\alpha}} U & \left(\frac{1}{2}-a\right) b \rho b S C_{l_{\alpha}} U & 0 \\
-\rho b^{2} S C_{m_{\alpha, e f f}} U & c_{\alpha}-\left(\frac{1}{2}-a\right) b \rho b^{2} S C_{m_{\alpha, e f f}} U & 0 \\
0 & 0 & c_{\beta_{\text {servo }}}
\end{array}\right)}_{\mathbf{C}_{\text {eom }}}\left(\begin{array}{c}
\dot{h} \\
\dot{\alpha} \\
\dot{\beta}
\end{array}\right)+ \\
& +\underbrace{\left(\begin{array}{ccc}
k_{h} & \rho b S C_{l_{\alpha}} U^{2} & \rho b S C_{l_{\beta}} U^{2} \\
0 & k_{\alpha}(\alpha)-\rho b^{2} S C_{m_{\alpha, e f f}} U^{2} & -\rho b^{2} S C_{m_{\beta, e f f}} U^{2} \\
0 & 0 & k_{\beta_{\text {servo }}}
\end{array}\right)}_{\mathbf{K}_{\text {eom }}}\left(\begin{array}{c}
h \\
\alpha \\
\beta
\end{array}\right)=\underbrace{\left(\begin{array}{c}
0 \\
0 \\
k_{\beta_{\text {servo }}}
\end{array}\right)}_{\mathbf{F}_{\text {eom }}} \mathbf{u} .
\end{aligned}
$$

where: $\mathbf{M}_{\text {eom }}$ is the mass matrix of the equation of motion, $\mathbf{C}_{e o m}$ is the damping matrix of the equation of motion, $\mathbf{K}_{\text {eom }}$ is the stiffness matrix of the equation of motion, $\mathbf{F}_{\text {eom }}$ is the forcing matrix of the equation of motion.

The equation above was converted into qLPV state space formulation as:

$$
\mathbf{x}(t)=\left(\begin{array}{c}
x_{1}(t) \\
x_{2}(t) \\
x_{3}(t) \\
x_{4}(t) \\
x_{5}(t) \\
x_{6}(t)
\end{array}\right)=\left(\begin{array}{c}
\dot{h} \\
\dot{\alpha} \\
\dot{\beta} \\
h \\
\alpha \\
\beta
\end{array}\right) \quad \text { and } \quad \mathbf{u}(t)=u_{\beta}
$$


with the state and input matrices given as:

$$
\mathbf{A}(\mathbf{p}(t))=\left(\begin{array}{cc}
-\mathbf{M}_{\text {eom }}^{-1} \mathbf{C}_{\text {eom }}(\mathbf{p}(t)) & -\mathbf{M}_{\text {eom }}^{-1} \mathbf{K}_{\text {eom }}(\mathbf{p}(t)) \\
-\mathbf{I} & 0
\end{array}\right), \quad \mathbf{B}=\left(\begin{array}{c}
\mathbf{M}_{\text {eom }}^{-1} \mathbf{F}_{\text {eom }} \\
0
\end{array}\right)
$$

In case $x_{5}(t)=\alpha$ is the only measurable state the output and feed-through matrices are the following:

$$
\mathbf{C}=\left(\begin{array}{llllll}
0 & 0 & 0 & 0 & 1 & 0
\end{array}\right), \quad \mathbf{D}=0 .
$$

The system matrix can be constructed in the following way:

$$
\mathbf{S}(\mathbf{p}(t))=\left(\begin{array}{cc}
\mathbf{A}(\mathbf{p}(t)) & \mathbf{B} \\
\mathbf{C} & \mathbf{D}
\end{array}\right)
$$

The system parameters are taken from [17], and they are the following:

$m_{h}=6.516 \mathrm{~kg} ; m_{\alpha}=6.7 \mathrm{~kg} ; m_{\beta}=0.537 \mathrm{~kg} ; x_{\alpha}=0.21 ; x_{\beta}=0.233 ; r_{\beta}=0 \mathrm{~m}$; $a=-0.673 \mathrm{~m} ; b=0.1905 \mathrm{~m} ; \hat{I}_{\alpha}=0.126 \mathrm{kgm}^{2} ; \hat{I}_{\beta}=10^{-5} ; c_{h}=27.43 \mathrm{Nms} / \mathrm{rad}$; $c_{\alpha}=0.215 \mathrm{Nms} / \mathrm{rad} ; c_{\beta_{\text {servo }}}=4.182 \times 10^{-4} \mathrm{Nms} / \mathrm{rad} ; k_{h}=2844 ; k_{\beta_{\text {servo }}}=7.6608 \times$ $10^{-3} ; \rho=1.225 \mathrm{~kg} / \mathrm{m}^{3} ; C_{l_{\alpha}}=6.757 ; C_{m_{\alpha, e f f}}=-1.17 ; C_{l_{\beta}}=3.774 ; C_{m_{\beta, e f f}}=-2.1$; $S=0.5945 \mathrm{~m}$.

\section{The Proposed Control Design Methodology}

\subsection{Reconstruction of the TP type polytopic model}

TP model transformation with its mathematical background and application in LMI based control design was introduced and elaborated in [24, 25, 26, 27, 23]. The most important definitions corresponding to TP model transformation and TP type polytopic representation are the following:

Definition 1 (Finite element TP type convex polytopic model - TP model): $\mathbf{S}(\mathbf{p}(t))$ in (7) for any parameter is given as the parameter-varying convex combination of LTI system matrices $\mathbf{S} \in \mathbb{R}^{O \times I}$.

$$
\mathbf{S}(\mathbf{p}(t))=\sum_{i_{1}=1}^{I_{1}} \sum_{i_{2}=1}^{I_{2}} . . \sum_{i_{N}=1}^{I_{N}} w_{n, i_{n}}\left(p_{n}(t)\right) \mathbf{S}_{i_{1}, i_{2}, . ., i_{N}}=\mathscr{S} \underset{n=1}{\otimes} \mathbf{w}_{n}\left(p_{n}(t)\right),
$$

where $\mathbf{p}(t) \in \Omega$. The coefficient tensor $\mathscr{S} \in \mathbb{R}^{I_{1} \times I_{2} \times \cdots \times I_{n} \times O \times I}$ has $N+2$ dimensions, it is constructed from the LTI vertex systems $\mathbf{S}_{i_{1}, i_{2}, \ldots, i_{N}}(8)$ and the row vector $\mathbf{w}_{n}\left(p_{n}(t)\right)$ 
contains one variable and continuous weighting functions $w_{n, i_{n}}\left(p_{n}(t)\right), i_{n}=1 \ldots I_{N}$. In order to get convex representation the weighting functions satisfy the following criteria:

$$
\begin{array}{r}
\forall n, i, p_{n}(t): w_{n, i}\left(p_{n}(t)\right) \in[0,1] \\
\forall n, p_{n}(t): \sum_{i=1}^{I_{n}} w_{n, i}\left(p_{n}(t)\right)=1 .
\end{array}
$$

Definition 2 (NO/CNO, NOrmal type TP model): The TP model is NO (normal) type model if its weighting functions are Normal, that is if it satisfies (9), (10), and the largest value of all weighting functions is 1 . The convex TP model is CNO (close to normal) if it satisfies (9), (10) and the largest value of all weighting functions is 1 or close to 1.

TP model transformation is a numerical method allowing the transformation of qLPV models given as (7) to TP type polytopic model defined in (8) enabling the immediate application of LMI based control design. TP model transformation is also capable to find TP type approximations of the original model with arbitrary accuracy. qLPV models can be given as analytical equations based on physical considerations, as the result of soft-computing based identification techniques, or as an outcome of blackbox identification. The transformation can be executed within a reasonable amount of time and can replace the analytical conversions by a tractable numerical operation carried out in a routine-like fashion.

\subsection{Uncertainty structure}

Based on the derivation presented in [28] it is assumed that the uncertain model takes the following structure:

$$
\begin{aligned}
\dot{x}(t)= & \left(\mathbf{A}(\mathbf{p}(t))+\mathbf{D}_{a}(\mathbf{p}(t)) \Delta_{a}(t) \mathbf{E}_{a}(\mathbf{p}(t))\right) x(t) \\
& \left(\mathbf{B}(\mathbf{p}(t))+\mathbf{D}_{b}(\mathbf{p}(t)) \Delta_{b}(t) \mathbf{E}_{b}(\mathbf{p}(t))\right) u(t),
\end{aligned}
$$

where the uncertain blocks $\Delta_{a}(t)$ and $\Delta_{b}(t)$ satisfy

$$
\begin{gathered}
\left\|\Delta_{a}(t)\right\| \leq \frac{1}{\gamma_{a}}, \quad \Delta_{a}(t)=\Delta_{a}^{T}(t), \\
\left\|\Delta_{b}(t)\right\| \leq \frac{1}{\gamma_{b}}, \quad \Delta_{b}(t)=\Delta_{b}^{T}(t)
\end{gathered}
$$

and $\mathbf{D}_{a}(\mathbf{p}(t)), \mathbf{E}_{a}(\mathbf{p}(t)), \mathbf{D}_{b}(\mathbf{p}(t))$ and $\mathbf{E}_{b}(\mathbf{p}(t))$ are known scaling matrices. 


\subsection{Control structure}

The implementation of full state feedback control is not always straightforward since in many cases the measurement of all states can lead to high sensor cost or measurement difficulties and in some cases the states do not correspond to physical values. In the present case it is assumed that only the pitch angle $\alpha$ of the NATA system is measured, therefore output feedback control structure is utilised. The observer has to be designed in such a way that it satisfies $\mathbf{x}(t)-\hat{\mathbf{x}}(t) \rightarrow 0$ as $t \rightarrow \infty$, where $\hat{\mathbf{x}}(t)$ denotes the state-vector estimated by the observer. Since parameter vector $\mathbf{p}(t)$ does not contain values from the estimated state-vector $\hat{\mathbf{x}}(t)$, the control design strategy presented in $[29,28]$ was utilised:

$$
\begin{aligned}
\hat{\mathbf{x}}(t) & =\mathbf{A}(\mathbf{p}(t)) \hat{\mathbf{x}}(t)+\mathbf{B}(\mathbf{p}(t)) \mathbf{u}(t)+\mathbf{K}(\mathbf{p}(t))(\mathbf{y}(t)-\hat{\mathbf{y}}(t)) \\
\hat{\mathbf{y}}(t) & =\mathbf{C}(\mathbf{p}(t)) \hat{\mathbf{x}}(t),
\end{aligned}
$$

where $\mathbf{u}(t)=-\mathbf{F}(\mathbf{p}(t)) \mathbf{x}(t)$.

The current investigation applies a control design strategy that yields a controller and an observer, which have share the same polytopic structure of the model itself as:

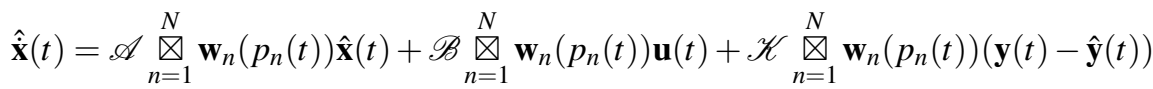

$$
\begin{aligned}
& \hat{\mathbf{y}}(t)=\mathscr{C} \underset{n=1}{\mathbb{N}} \mathbf{w}_{n}\left(p_{n}(t)\right) \hat{\mathbf{x}}(t) \\
& \mathbf{u}(t)=-\left(\mathscr{F} \bigotimes_{n=1}^{N} \mathbf{w}_{n}\left(p_{n}(t)\right)\right) \mathbf{x}(t) .
\end{aligned}
$$

The control design aims in determining gains $\mathscr{F}$ and $\mathscr{K}$ that lead to stable outputfeedback control structure. The LTI feedback gains $\mathbf{F}_{i_{1}, i_{2}, \ldots, i_{N}}$ and LTI observer gains $\mathbf{K}_{i_{1}, i_{2}, \ldots, i_{N}}$ are stored in tensor $\mathscr{F}$ and $\mathscr{K}$, which are called vertex feedback and observer gains.

\subsection{Control performance specifications formulated in terms of LMIs}

A large number LMIs guaranteeing various control performance specification has been developed for polytopic systems, which can be readily applied to design vertex controller and observer gains. The control performance objectives of the present investigation are the following: 
- Asymptotically stable controller and observer;

- Robust stability of the controller for parameter uncertainties.

- Constrain on the control value.

LMI theorems derived in [28] are selected for the control design.

Theorem 1 (Globally and asymptotically stable controller for uncertain qLPV systems) A controller stabilising the uncertain qLPV system (11) can be obtained by solving the following LMIs for $\mathbf{P}>\mathbf{0}$ and $\mathbf{M}_{r}(r=1, \ldots, R)$

$$
\begin{aligned}
& \mathbf{S}_{r r}<\mathbf{0}, \\
& \mathbf{T}_{r s}<\mathbf{0},
\end{aligned}
$$

where

$$
\mathbf{S}_{r r}=\left(\begin{array}{ccccc}
\left(\mathbf{P} \mathbf{A}_{r}^{T}+\mathbf{A}_{r} \mathbf{P}-\mathbf{B}_{r} \mathbf{M}_{r}-\mathbf{M}_{r}^{T} \mathbf{B}_{r}^{T}\right) & \mathbf{D}_{a r} & \mathbf{D}_{b r} & \mathbf{P} \mathbf{E}_{a r}^{T} & -\mathbf{M}_{r}^{T} \mathbf{E}_{b r}^{T} \\
\mathbf{D}_{a r}^{T} & -\mathbf{I} & 0 & 0 & 0 \\
\mathbf{D}_{b r}^{T} & 0 & -\mathbf{I} & 0 & 0 \\
\mathbf{E}_{a r} \mathbf{P} & 0 & 0 & -\gamma_{a}^{2} \mathbf{I} & 0 \\
-\mathbf{E}_{b r} \mathbf{M}_{r} & 0 & 0 & 0 & -\gamma_{b}^{2} \mathbf{I}
\end{array}\right),
$$

and

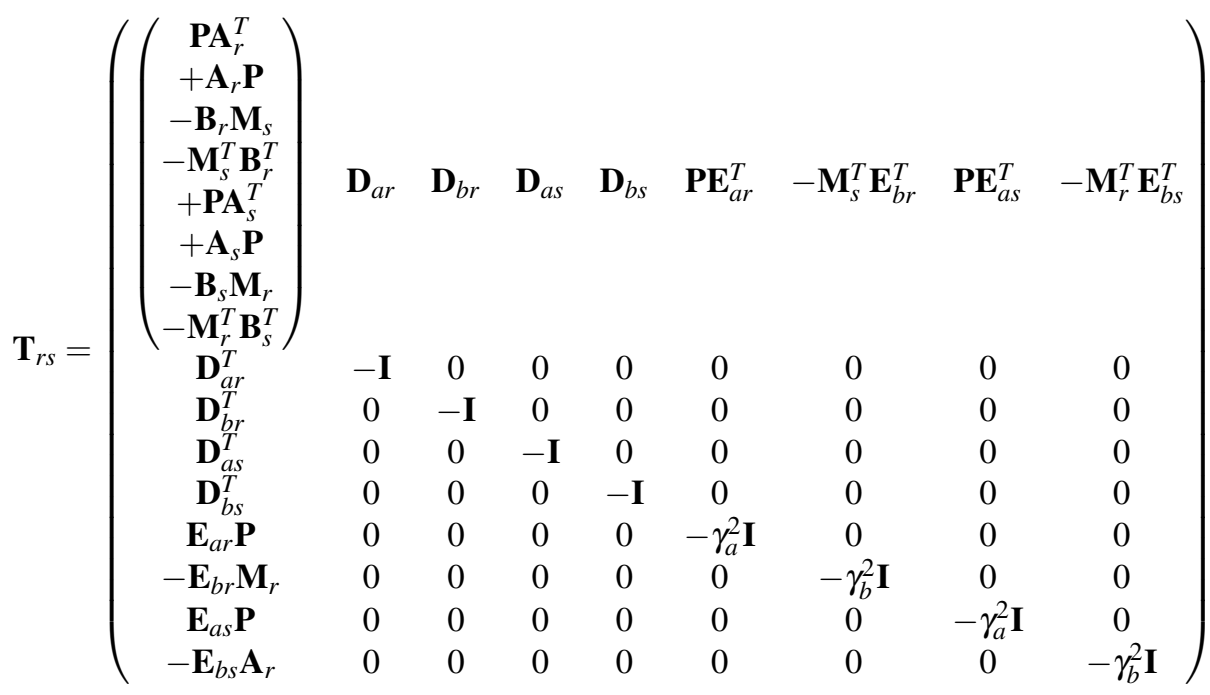


for $r<s \leq R$, except the pairs $(r, s)$ such that $\forall \mathbf{p}(t): w_{r}(\mathbf{p}(t)) w_{s}(\mathbf{p}(t))=0$ and where $\mathbf{M}_{r}=\mathbf{F}_{r} \mathbf{P}$.

The feedback gains can be obtained from the solution of the above LMIs as $\mathbf{F}_{r}=\mathbf{M}_{r} \mathbf{P}^{-1}$.

Theorem 2 (Globally and asymptotically stable controller with constraint on the control value) The simultaneous solution of the LMIs of Theorem 1 and Theorem 2 in the form of:

$$
\begin{gathered}
\phi^{2} \mathbf{I} \leq \mathbf{P} \\
\left(\begin{array}{cc}
\mathbf{P} & \mathbf{M}_{r}^{T} \\
\mathbf{M}_{r} & \mu^{2} \mathbf{I}
\end{array}\right) \geq 0
\end{gathered}
$$

yields an asymptotically stable controller, where $\|\mathbf{u}(t)\|_{2} \leq \mu$ is enforced at all time and $\|\mathbf{x}(0)\|_{2} \leq \phi$.

Theorem 3 (Globally and asymptotically stable observer) Assume the polytopic model (8) and a control structure as given by (14). An asymptotically stable observer can be obtained by solving the following LMIs for $\mathbf{P}>\mathbf{0}$ and $\mathbf{N}_{r}(r=1, \ldots, R)$ :

$$
\begin{aligned}
\mathbf{A}_{r}^{T} \mathbf{P}-\mathbf{C}_{r}^{T} \mathbf{N}_{r}^{T}+\mathbf{P} \mathbf{A}_{r}-\mathbf{N}_{r} \mathbf{C}_{r} & <\mathbf{0}, \\
\mathbf{A}_{r}^{T} \mathbf{P}-\mathbf{C}_{s}^{T} \mathbf{N}_{r}^{T}+\mathbf{P} \mathbf{A}_{r}-\mathbf{N}_{r} \mathbf{C}_{s}+\mathbf{A}_{s}^{T} \mathbf{P}-\mathbf{C}_{r}^{T} \mathbf{N}_{2}^{T}+\mathbf{P} \mathbf{A}_{s}-\mathbf{N}_{s} \mathbf{C}_{r} & <\mathbf{0}
\end{aligned}
$$

for $r<s \leq R$, except the pairs $(r, s)$ such that $\forall \mathbf{p}(t): w_{r}(\mathbf{p}(t)) w_{s}(\mathbf{p}(t))=0$, and where $\mathbf{N}_{r}=\mathbf{P K}_{r}$. The observer gains can derived from the solution of the above LMIs as $\mathbf{K}_{r}=\mathbf{P}^{-1} \mathbf{N}_{r}$.

\section{Control Design Results}

\subsection{TP model transformation of the NATA model}

The first step of the control design is to obtain a polytopic form of the NATA model. This step was achieved by the execution of TP model transformation on the state matrix of the NATA model given by (5). Prior executing TP model transformation the transformation space $\Omega$ and the discretization grid $M$ has to be defined. $\Omega$ was defined in the interval $U \in[8,20](\mathrm{m} / \mathrm{s})$ and $\alpha \in[-0.3,0.3](\mathrm{rad})$ and the discretization grid is defined as $M_{1} \times M_{2}$, where $M_{1}=137$ and $M_{2}=137$. The HOSVD-based canonical form for the discretized tensor $\mathscr{S}^{D} \in \mathbb{R}^{M_{1} \times M_{2} \times 7 \times 7}$ results in rank 2 in the first dimension and rank 3 in the second dimension. The exact CNO type convex representation of the NATA model can be given by 6 vertex LTI systems, the same number as in the case of the HOSVD-based canonical form. The weighting functions 
$w_{1, i}(U), i=1 . .2$, and $w_{2, j}(\alpha), j=1 . .3$ of the HOSVD-based canonical form and the CNO type convex form are depicted in Figure 1.
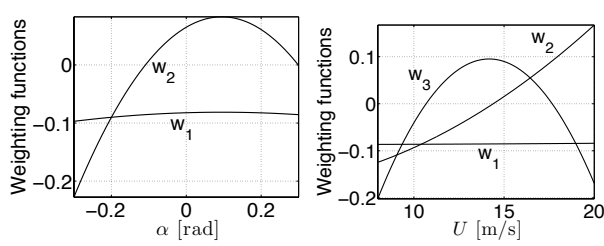

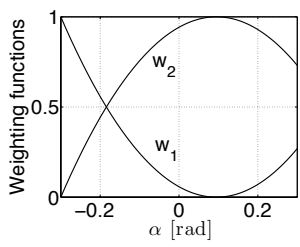

Figure 1

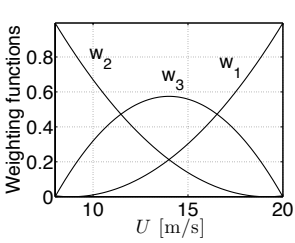

HOSVD-based canonical (left) and CNO type (right) weighting functions of the dimensions $\alpha$ and $U$.

\subsection{LMI-based output feedback controller design}

\subsubsection{Defining the uncertainty in the trailing-edge servo-motor dynamics}

The trailing-edge servo-motor was investigated in [17] resulting in dynamics as given in (3) with parameters $k_{\beta_{\text {servo }}}$ and $c_{\beta_{\text {servo }}}$. However, it can be assumed that the values of these parameters have some uncertainty, therefore the aim of this section is to define the uncertain structure of the trailing-edge servo-motor dynamics based on (11) in order to design a control system, which can asymptotically stabilize the uncertain qLPV system.

Parameter $k_{\beta_{\text {servo }}}$ appears in elements $A_{16}(\mathbf{p}(t)), A_{26}(\mathbf{p}(t))$ and $A_{36}(\mathbf{p}(t))$ of state matrix $\mathbf{A}(\mathbf{p}(t))$ and in elements $B_{11}, B_{21}$ and $B_{31}$ of input matrix $\mathbf{B}$ while parameter $c_{\beta_{\text {servo }}}$ appears in elements $A_{13}, A_{23}$ and $A_{33}$ of state matrix $\mathbf{A}(\mathbf{p}(t))$ based on which the uncertain blocks $\Delta_{a}(t)$ and $\Delta_{b}(t)$ can be defined as:

$$
\Delta_{a}(t)=\left(\begin{array}{cc}
\Delta_{k_{\beta_{\text {servo }}}}(t) & 0 \\
0 & \Delta_{\text {舡rvo }}(t)
\end{array}\right)
$$

and

$$
\Delta_{b}(t)=\left(\Delta_{k_{\beta_{\text {servo }}}}(t)\right)
$$

where functions $\Delta_{k_{\beta_{\text {servo }}}}(t)$ and $\Delta_{c_{\beta_{\text {servo }}}}(t)$ are bounded functions representing the discrepancy between the actual and nominal values of parameters $k_{\beta_{\text {servo }}}$ and $c_{\beta_{\text {servo }}}$ respectively.

In order to match the uncertain parameters with the corresponding elements of the system matrix $\mathbf{S}(\mathbf{p}(t))$ scaling matrices $\mathbf{D}_{a}(\mathbf{p}(t)), \mathbf{E}_{a}(\mathbf{p}(t)), \mathbf{D}_{b}(\mathbf{p}(t))$ and $\mathbf{E}_{b}(\mathbf{p}(t))$ have to be defined. 
Proposition 1 There are two basic possibilities in constructing the scaling matrices which results in the same overall uncertain structure of (11), however, the different structures can highly influence the LMI feasibility tests (see results in the following section).

\section{Uncertainty structure 1}

$$
\mathbf{D}_{a}=\left(\begin{array}{cc}
-\mathbf{M}_{\text {eom }}^{-1} c_{\beta_{\text {servo }}} & -\mathbf{M}_{\text {eom }}^{-1} k_{\beta_{\text {servo }}} \\
-\mathbf{M}_{\text {eom }}^{-1} c_{23} c_{\text {servo }} & -\mathbf{M}_{\text {eom }}^{-1} k_{\beta_{\text {servo }}} \\
-\mathbf{M}_{\text {eom }}^{-1} c_{33} \beta_{\text {servo }} & -\mathbf{M}_{\text {eom }}^{-1} k_{33} k_{\text {servo }} \\
0 & 0 \\
0 & 0 \\
0 & 0
\end{array}\right), \quad \mathbf{E}_{a}=\left(\begin{array}{cccccc}
0 & 0 & 1 & 0 & 0 & 0 \\
0 & 0 & 0 & 0 & 0 & 1
\end{array}\right)
$$

and

$$
\mathbf{D}_{b}^{T}=\left(\begin{array}{lllllll}
\mathbf{M}_{\text {eom } 13}^{-1} k_{\beta_{\text {servo }}} & \mathbf{M}_{\text {eom } 23}^{-1} k_{\beta_{\text {servo }}} & \mathbf{M}_{\text {eom }}^{-1} k_{3} & \beta_{\text {servo }} & 0 & 0 & 0
\end{array}\right), \quad \mathbf{E}_{b}=1 .
$$

\section{Uncertainty structure 2}

$$
\mathbf{D}_{a}=\left(\begin{array}{cc}
-\mathbf{M}_{\text {eom }}^{-1} & -\mathbf{M}_{\text {oom }}^{-1} \\
-\mathbf{M}_{\text {eom }}^{-1} & -\mathbf{M}_{\text {eom }}^{-1} \\
-\mathbf{M}_{\text {eom }}^{-1} & -\mathbf{M}_{\text {eom }}^{-1} \\
0 & 0 \\
0 & 0 \\
0 & 0
\end{array}\right), \quad \mathbf{E}_{a}=\left(\begin{array}{cccccc}
0 & 0 & c_{\beta_{\text {servo }}} & 0 & 0 & 0 \\
0 & 0 & 0 & 0 & 0 & k_{\beta_{\text {servo }}}
\end{array}\right)
$$

and

$$
\mathbf{D}_{b}^{T}=\left(\begin{array}{llllll}
\mathbf{M}_{\text {eom }}^{-1} & \mathbf{M}_{\text {eom } 23}^{-1} & \mathbf{M}_{\text {eom }}^{-1} & 0 & 0 & 0
\end{array}\right), \quad \mathbf{E}_{b}=k_{\beta_{\text {servo }}} .
$$

\subsubsection{Control design results}

The CNO type convex polytopic representation on the NATA model can be immediately applied for LMI-based control design. The following controllers and observers were designed based on various control performance specifications for both Uncertainty structure 1 and Uncertainty structure 2. 
Proposition 2 Defining the maximal allowable difference between the nominal and actual values of parameters $k_{\beta_{\text {servo }}}$ and $c_{\beta_{\text {servo }}}$ for a given control solution can be done in the following way:

Recall that the uncertain blocks $\Delta_{a}(t)$ and $\Delta_{b}(t)$ were defined as

$$
\Delta_{a}(t)=\left(\begin{array}{cc}
\Delta_{k_{\beta_{\text {servo }}}}(t) & 0 \\
0 & \Delta_{c_{\beta_{\text {servo }}}}(t)
\end{array}\right), \quad \Delta_{b}(t)=\left(\Delta_{k_{\beta_{\text {servo }}}}(t)\right)
$$

and they satisfy

$$
\left\|\Delta_{a}(t)\right\| \leq \frac{1}{\gamma_{a}}, \quad\left\|\Delta_{b}(t)\right\| \leq \frac{1}{\gamma_{b}} .
$$

Since $\Delta_{a}(t)$ is a diagonal matrix it has a norm that equals the absolute value of its largest element; $\Delta_{b}(t)$ is a scalar value having a norm equal to its absolute value. Matrix $\Delta_{a}(t)$ contains $\Delta_{b}(t)$, therefore $\gamma_{a}$ can be set to equal $\gamma_{b}$. The maximal discrepancy of the two parameters are given as

$$
\begin{aligned}
& \Delta_{k_{\beta_{\text {servo }}}^{\max }}^{\max }=\frac{1}{\gamma_{a}} \geq\left|\Delta_{k_{\beta_{\text {servo }}}}(t)\right| ; \\
& \Delta_{c_{\beta_{\text {servo }}}^{\max }}^{\max }=\frac{1}{\gamma_{a}} \geq\left|\Delta_{c_{\beta_{\text {servo }}}}(t)\right|,
\end{aligned}
$$

where superscript "max" stands for the maximal allowable difference.

In the following the differentiation for Control solution $n .1$ and $n .2$ stands for Uncertainty structure 1 and 2 respectively.

\section{Control solution 1.1 and 1.2}

Control solutions 1.1 and 1.2 were designed with the aim to find the minimal value for $\gamma_{a}=\gamma_{b}$ allowing the maximal uncertainties in parameters $k_{\beta_{\text {servo }}}$ and $c_{\beta_{\text {servo }}}$ the controller can asymptotically stabilize. The feedback gains were designed by applying the LMIs from Theorem 1 and the observer gains by applying LMIs from Theorem 3.

Control solution 1.1 achieved $\gamma_{a_{\text {min }}}=\gamma_{b_{\text {min }}}=1.44$ while control solution 1.2 resulted in $\gamma_{a_{\min }}=\gamma_{b_{\min }}=1.77$.

\section{Control solution 2.1 and 2.2}

The aim in designing Control solutions 2.1, 2.2, 3.1, 3.2, 4.1 and 4.2 was to find a trade-off between the maximal allowable parameter discrepancy and keeping the 
control signal as low as possible. The feedback gains were derived by applying the LMIs from Theorems 1 and 2 with the initial state condition bound set as $\phi=0.002$ for each design. The observer gains for each solution were derived by applying LMIs from Theorem 3.

In case of Control solution 2.1 and 2.2 the maximal allowable discrepancy between the nominal and actual parameter was set to $50 \%$ resulting in $\gamma_{a_{\min }}=\gamma_{b_{\min }}=2$. The minimal values for the control constrain $\mu$ that leads to feasible controller was $\mu_{\min }=44$ for Control solution 2.1 and $\mu_{\min }=13286$ for Control solution 2.2.

\section{Control solution 3.1 and 3.2}

$\gamma_{a_{\min }}=\gamma_{b_{\min }}=5$ was set for Control solution 3.1 and 3.2 yielding feasible solutions with $\mu_{\min }=26$ for Control solution 3.1 and $\mu_{\min }=3672$ for Control solution 3.2.

\section{Control solution 4.1 and 4.2}

The minimal value of $\mu_{\min }=22$ for Control solution 4.1 and $\mu_{\min }=3595$ for Control solution 4.2 was achieved by setting $\gamma_{a_{\min }}=\gamma_{b_{\min }}=10$.

\section{Simulation Results and Evaluation}

\subsection{Simulation}

The responses of the control solutions were verified by numerical simulations. The base free stream velocity is chosen to equal $U=14.1 \mathrm{~m} / \mathrm{s}$ for two reasons; first, it belongs to the critical free stream velocity range where the NATA model exhibits limit cycle oscillations, second, to be comparable with the results of several previous papers, which used the same speed in their measurements or simulations. The controller was turned off for five seconds at each simulation to let the oscillations develop, but the figures bellow show only that part of the responses where the controller is turned on.

Each controller was tested in two simulation cases:

- Simulation case 1 represents the response without any perturbations. In order to fully test the allowable uncertainty ranges, functions $\Delta_{k_{\beta_{s e r v o}}}(t)$ and $\Delta_{c_{\beta_{\text {servo }}}}(t)$ were set as:

$$
\begin{aligned}
& -\Delta_{k_{\beta_{\text {servo }}}}(t)=\frac{1}{\gamma_{a_{\min }}} \sin \left(6 \pi t+\frac{\pi}{2}\right) ; \\
& -\Delta_{c_{\beta_{\text {servo }}}}(t)=\frac{1}{\gamma_{a_{\min }}} \sin (10 \pi t) ;
\end{aligned}
$$


where $\gamma_{a_{\min }}$ takes the minimal value corresponding to each control solution.

- Simulation case 2 represents system that has several perturbations that can occur during physical implementation. Simualtion case 1 was extended with the following perturbations:

- the computational delay is represented by $1 \mathrm{~ms}$ constant time delay;

- the control signal is saturated at $\pm 2[\mathrm{rad} / \mathrm{s}]$;

- the sensor noise is represented by normally distributed random noise with $10 \%$ variance;

- the free stream velocity varies as $U(t)=14.1+5 \sin (2 \pi t)$;

- input disturbance $u_{d}(t)=\frac{30}{180} \pi$ is added to the control signal 1 second after the controller is turned on;

Figures 2 and 3 show the time response of the closed loop system for Control solution 2.1 and 2.2 for Simulation case 1, Control solution 2.1 and 2.2 for Simulation case 2, Control solution 3.1 and 3.2 for Simulation case 1 and Control solution 3.1 and 3.2 for Simulation case 1 respectively.

\subsection{Evaluation}

Each control solution can asymptotically stabilise the NATA model, however, it is important to note that the control solutions guarantee stability within the domain $\Omega$. The control performance of each control solution is evaluated based on the maximal allowable parameter uncertainty, maximal control signal and settling time.

- Control solution 1.1 and 1.2 - maximal allowable parameter uncertainty (70\% for solution 1.1 and $56.5 \%$ for solution 1.2); very high control signal $\left(u_{\max }\right.$ is in the order of magnitude of $10^{5}$ ); settling time approximately $1 \mathrm{~s}$ for Simulation case 1 . Control solutions 1.1 and 1.2 were not able to stabilize the NATA system as the high feedback gains lost stability due to the time delay in Simulation case 2. Difficult for practical implementation due to high control signals.

- Control solution 2.1 and 2.2 - high allowable parameter uncertainty (50\%), high control signal magnitude $\left(u_{\max }=150\right.$ for Control solution 2.1 and $u_{\max }=$ 250 for Control solution 2.2); settling time approximately $1 s$ for Simulation case 1 and approximately $1.5 \mathrm{~s}$ for Simulation case 2 . High allowable parameter uncertainty for acceptable control signal magnitude.

- Control solution 3.1 and 3.2 - acceptable allowable parameter uncertainty (20\%), low control signal magnitude $\left(u_{\max }=35\right.$ for Control solution 3.1 and 

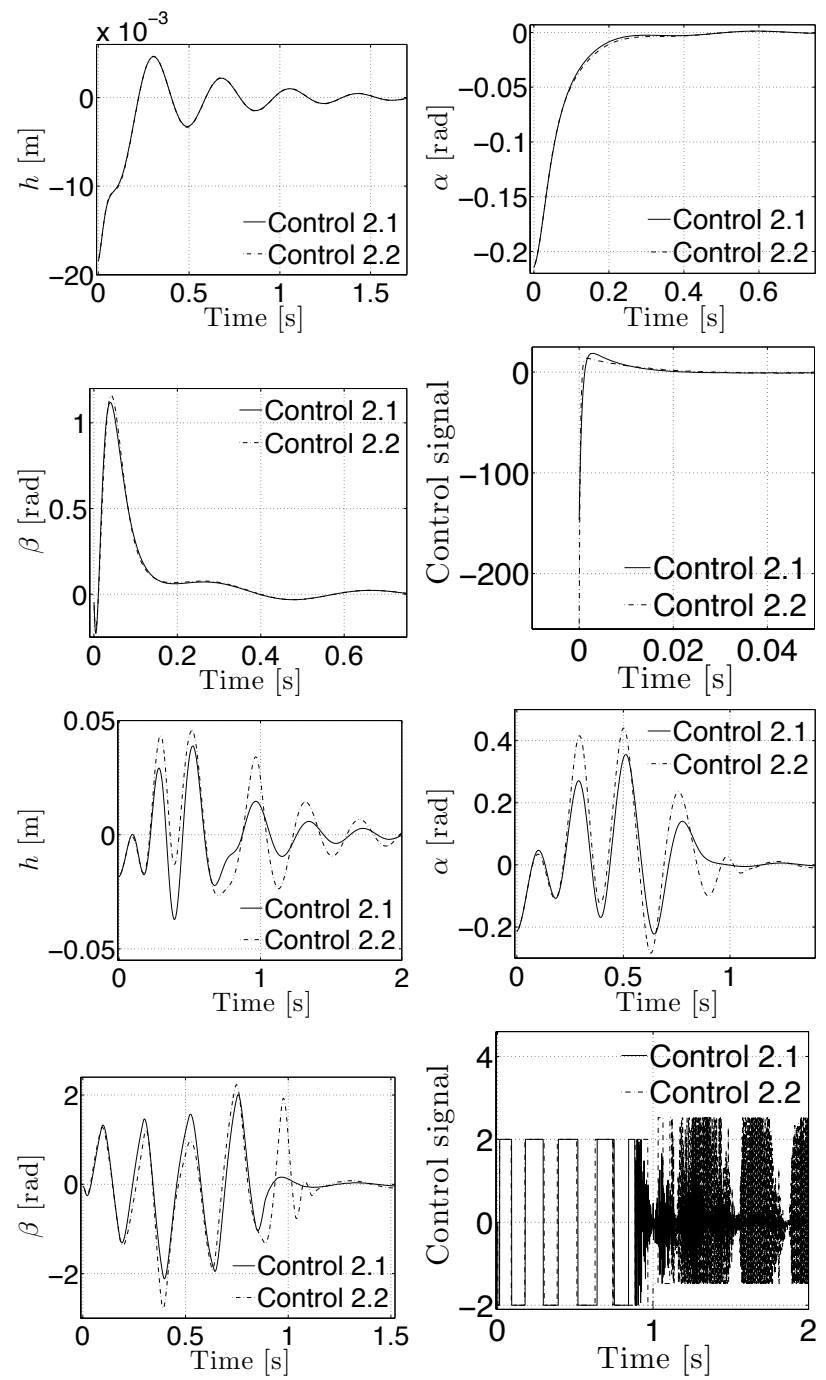

Figure 2

Time response of Control solution 2.1 and 2.2 for Simulation case 1 (first row) and Simulation case 2 (second row).

$u_{\max }=7.8$ for Control solution 3.2); settling time approximately $1 s$ for Simulation case 1 and approximately $1.5 \mathrm{~s}$ for Simulation case 2 . Low control signal magnitude for acceptable parameter uncertainty.

- Control solution 4.1 and 4.2 - minimal allowable parameter uncertainty (10\%), smallest control signal $\left(u_{\max }=15\right.$ for Control solution 4.1 and $u_{\max }=7$ for Control solution 4.2); settling time approximately $1 s$ for Simulation case 1 and 

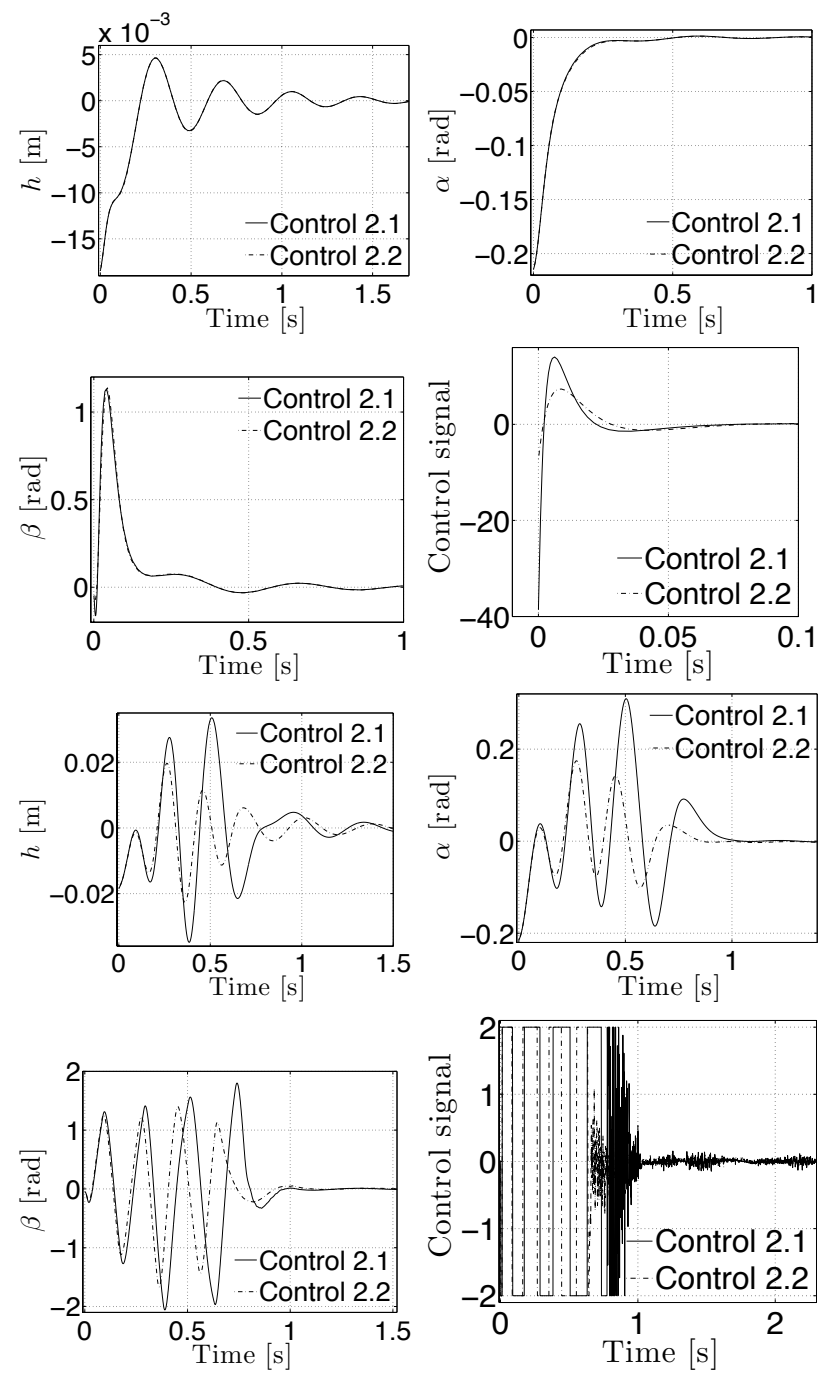

Figure 3

Time response of Control solution 3.1 and 3.2 for Simulation case 1 (1. and 2. row) and Simulation case 2 (3. and 4. row).

approximately $1.5 \mathrm{~s}$ for Simulation case 2. Further decrease in the allowable uncertainty does not decrease the control signal significantly.

Generally, it can be concluded that maximising the allowable parameter uncertainties without a constrain on the control value leads to unacceptably high control signals. On the other hand, it is possible to find a trade-off between the maximal acceptable 
uncertainty and the limit of the control signal magnitude. In this term, Control solution 3.2 achieved the best results in the simulations. Control solution 2.1 can be a chosen in case higher uncertainty is a requiremed. Decreasing the allowable uncertainty to very low levels however, does not results in significant decrease in the control signal magnitude.

It can be noted that it is worth to test various uncertainty structures (Uncertainty structure 1 and 2 in the present case), as it highly influences the LMI feasibility results. Uncertainty structure 1 led to better control performance at higher allowable uncertainties, while Uncertainty structure 2 was more favourable at lower parameter uncertainties.

There is no significant difference in the settling time in any control solution.

The LMIs defining the constrain on the control signal lead to large differences between the smallest control signal bounds in case of Uncertainty structure 1 and 2, which imply high conservativity of bound $\mu$, however, within the same uncertainty structure it can indicate the control signal magnitude effectively.

The control performance of the derived solutions can be compared to results found in other publications dealing with the same NATA model. LQR controller was designed in [17] with somewhat longer settling time and lower control signals, however, the model has nonlinearity only in the dimension of $U$ and full state feedback is utilised instead of output feedback. Similar control performance was achieved in [23] and in [18], which was expected as the same control design methodology was utilised. However, [18] designed controller for the 2 DoF NATA model, while there is no robustness involved in the control design of [23]. LQR based output feedback controller is designed in [30] with similar control performance as Simulation case 1 in the present investigation.

\section{Conclusions}

The proposed control design strategy based on Tensor Product model transformation can be executed systematically in a routine-like fashion and can include various forms control performance specifications formulated in terms of Linear Matrix Inequalities. The paper gives a robust stabilising output feedback control solution for the three degrees-of-freedom Nonlinear Aeroelastic Test Apparatus that can involve parameter uncertainties. Finding an acceptable trade-off between maximal allowable uncertainties and the upper bound of the control signal value was straightforward based on the systematic execution of the numerical control design. It was shown that varying the structure of the same uncertainty of quasi-Linear Parameter Varying systems can highly influence the feasibility tests of Linear Matrix Inequalities and thus the resulting control performance. Both, out of the two possible uncertainty structures available, can lead to good control performance depending the actual specifications, meaning it is worthwhile to investigate both structures for the given task. 


\section{Acknowledgements}

The research was supported by the Hungarian National Development Agency, (ERCHU-09-1-2009-0004, MTASZTAK) (OMFB-01677/2009).

The research was part of the Zoltán Magyary Postdoctoral Scholarship.

This research was supported by the European Union and the State of Hungary, co-financed by the European Social Fund in the framework of TÁMOP 4.2.4. A/111-1-2012-0001 'National Excellence Program'.

Takarics Béla publikációt megalapozó kutatása a TÁMOP 4.2.4.A/1-11-1-2012-0001 azonosító számú Nemzeti Kiválóság Program - Hazai hallgatói, illetve kutatói személyi támogatást biztosító rendszer kidolgozása és múködtetése országos program címú kiemelt projekt keretében zajlott. A projekt az Európai Unió támogatásával, az Európai Szociális Alap társfinanszírozásával valósul meg.

\section{References}

[1] V. Mukhopadhyay, "Historical perspective on analysis and control of aeroelastic responses," Journal of Guidance, Control, and Dynamics, vol. 26, pp. 673-684, Sep. 2003. [Online]. Available: http://doi.aiaa.org/10.2514/2.5108

[2] J. J. Block, Active control of an aeroelastic structure. Texas A\&M University, 1996.

[3] J. J. Block and T. W. Strganac, "Applied active control for a nonlinear aeroelastic structure," Journal of Guidance, Control, and Dynamics, vol. 21, pp. 838-845, Nov. 1998. [Online]. Available: http://doi.aiaa.org/10.2514/2.4346

[4] T. W. Strganac, J. Ko, and D. E. Thompson, "Identification and control of limit cycle oscillations in aeroelastic systems," Journal of Guidance, Control, and Dynamics, vol. 23, pp. 1127-1133, Nov. 2000.

[5] J. Ko, A. J. Kurdila, and T. W. Strganac, "Stability and control of a structurally nonlinear aeroelastic system," Journal of Guidance, Control, and Dynamics, vol. 21, pp. 718-725, Sep. 1998. [Online]. Available: http://doi.aiaa.org/10.2514/2.4317

[6] J. Ko, T. W. Strganac, and A. J. Kurdila, "Adaptive feedback linearization for the control of a typical wing section with structural nonlinearity," Nonlinear Dynamics, vol. 18, no. 3, pp. 289-301, 1999, 10.1023/A:1008323629064. [Online]. Available: http://dx.doi.org/10.1023/A:1008323629064

[7] G. Platanitis and T. Strganac, "Control of a nonlinear wing section using leading- and Trailing-Edge surfaces," Journal of Guidance, Control, and Dynamics, vol. 27, pp. 52-58, Jan. 2004. [Online]. Available: http://doi.aiaa.org/10.2514/1.9284 
[8] —, "Suppression of control reversal using leading- and Trailing-Edge control surfaces," Journal of Guidance, Control, and Dynamics, vol. 28, pp. 452-460, May 2005. [Online]. Available: http://doi.aiaa.org/10.2514/1.6692

[9] W. Xing and S. N. Singh, "Adaptive output feedback control of a nonlinear aeroelastic structure," Journal of Guidance, Control, and Dynamics, vol. 23, pp. 1109-1116, Nov. 2000. [Online]. Available: http://doi.aiaa.org/10.2514/2.4662

[10] S. N. Singh and L. Wang, "Output feedback form and adaptive stabilization of a nonlinear aeroelastic system," Journal of Guidance, Control, and Dynamics, vol. 25, pp. 725-732, Jul. 2002. [Online]. Available: http://doi.aiaa.org/10.2514/2.4939

[11] S. Singh, "State feedback control of an aeroelastic system with structural nonlinearity," Aerospace Science and Technology, vol. 7, pp. 23-31, Jan. 2003.

[12] K. K. Reddy, J. Chen, A. Behal, and P. Marzocca, "Multi-Input/Multi-Output adaptive output feedback control design for aeroelastic vibration suppression," Journal of Guidance, Control, and Dynamics, vol. 30, pp. 1040-1048, Jul. 2007. [Online]. Available: http://doi.aiaa.org/10.2514/1.27684

[13] K. W. Lee and S. N. Singh, "Multi-Input Noncertainty-Equivalent adaptive control of an aeroelastic system," Journal of Guidance, Control, and Dynamics, vol. 33, pp. 1451-1460, Sep. 2010. [Online]. Available: http://doi.aiaa.org/10.2514/1.48302

[14] R. C. Scott and L. E. Pado, "Active control of wind-tunnel model aeroelastic response using neural netwroks," Journal of Guidance, Control, and Dynamics, vol. 23, no. 6, pp. 1100-1108, 2000.

[15] Z. Wang, A. Behal, and P. Marzocca, "Model-Free control design for Multi-Input Multi-Output aeroelastic system subject to external disturbance," Journal of Guidance, Control, and Dynamics, vol. 34, pp. 446-458, Mar. 2011. [Online]. Available: http://doi.aiaa.org/10.2514/1.51403

[16] Z. Prime, B. Cazzolato, and C. Doolan, "A mixed H2/Hx scheduling control scheme for a two degree-of-freedom aeroelastic system under varying airspeed and gust conditions," in Proceedings of the AIAA Guidance, Navigation and Control Conference and Exhibit, Honolulu, Hawaii, 2008, pp. 1-16.

[17] Z. Prime, B. Cazzolato, C. Doolan, and T. Strganac, "Linear-Parameter-Varying control of an improved Three-Degree-of-Freedom aeroelastic model," Journal of Guidance, Control, and Dynamics, vol. 33, Mar. 2010. [Online]. Available: http://doi.aiaa.org/10.2514/1.45657

[18] P. Baranyi, "Tensor product Model-Based control of Two-Dimensional aeroelastic system," Journal of Guidance, Control, and Dynamics, vol. 29, pp. 391-400, Mar. 2006. [Online]. Available: http://doi.aiaa.org/10.2514/1.9462 
[19] - "Output feedback control of Two-Dimensional aeroelastic system," Journal of Guidance, Control, and Dynamics, vol. 29, pp. 762-767, May 2006. [Online]. Available: http://doi.aiaa.org/10.2514/1.14981

[20] P. Grof, P. Baranyi, and P. Korondi, "Convex hull manipulation based control performance optimisation," WSEAS Transactions on Systems and Control, vol. 5, no. 8, pp. 691-700, Aug. 2010, stevens Point, Wisconsin, USA.

[21] J. J. Block and H. Gilliat, "Active control of an aeroelastic structure," in AIAA Meeting Papers on Disc. Reno, NV: American Institute of Aeronautics and Astronautics, Inc., Jan. 1997, pp. 1-11.

[22] B. Takarics, P. Grof, P. Baranyi, and P. Korondi, "Friction compensation of an aeroelastic wing - a TP model transformation based approach." IEEE, Sep. 2010, pp. 527-533.

[23] B. Takarics and P. Baranyi, "Tensor-product-model-based control of a three degrees-of-freedom aeroelastic model," Journal of Guidance, Control, and Dynamics, vol. 36, no. 5, pp. 1527-1533, Sep. 2013.

[24] P. Baranyi, L. Szeidl, P. Várlaki, and Y. Yam, "Definition of the HOSVD-based canonical form of polytopic dynamic models," in 3rd International Conference on Mechatronics (ICM 2006), Budapest, Hungary, July 3-5 2006, pp. 660-665.

[25] P. Baranyi, "TP model transformation as a way to LMI based controller design," IEEE Transaction on Industrial Electronics, vol. 51, no. 2, pp. 387-400, April 2004.

[26] P. Baranyi, L. Szeidl, P. Várlaki, and Y. Yam, "Numerical reconstruction of the HOSVD-based canonical form of polytopic dynamic models," in 10th International Conference on Intelligent Engineering Systems, London, UK, June 26-28 2006, pp. 196-201.

[27] P. Galambos and P. Baranyi, "Trepresenting the model of impedance controlled robot interaction with feedback delay in polytopic lpv form: Tp model transformation based approach," Acta Polytechnica Hungarica, vol. 10, no. 1, pp. 139-157, Jan. 2013.

[28] K. Tanaka and H. O. Wang, Fuzzy Control Systems Design and Analysis: A Linear Matrix Inequality Approach. John Wiley \& Sons, Inc., 2001.

[29] C. W. Scherer and S. Weiland, Linear Matrix Inequalities in Control. DISC course lecture notes, 2000, http://w3.ele.tue.nl/fileadmin/ele/MBS/CS/Files/Courses/DISClmi/lmis1.pdf, retrieved on 05.02.2012.

[30] N. Bhoir, "Output feedback nonlinear control of an aeroelastic system with unsteady aerodynamics," Aerospace Science and Technology, vol. 8, pp. 195205, Apr. 2004. 